\title{
International Journal of Cerebrovascular Disease and Stroke
}

Batum M, et al. Int J Cerebrovasc Dis Stroke : IJCDS-107.

\section{The Coexistence of Familial Mediterranean Fever and Stroke}

\author{
Melike Batum", Aysin Kisabay", Merve Akgul, Deniz Selcuki \\ Department of Neurology, Faculty of Medicine, Celal Bayar University, Manisa, Turkey
}

"Corresponding author: Aysin Kisabay, Associate Professor, Faculty of Medicine, Department of Neurology, Celal Bayar University, Manisa, Turkey. Tel:+905362566809; Email: aysinkisabay@hotmail.com

${ }^{\#}$ Contributed equally to this work.

Citation: Batum M, Kisabay A, Akgul M, Selcuki D (2018) The Coexistence of Familial Mediterranean Fever and Stroke. Int J Cerebrovasc Dis Stroke : IJCDS-107. DOI: 10.29011/ IJCDS-107. 100007

Received Date: 13 August, 2018; Accepted Date: 21 August, 2018; Published Date: 28 August, 2018

\begin{abstract}
Familial Mediterranean Fever (FMF) is a hereditary disease that is characterized by fever, peritonitis, arthritis, skin lesions in the form of erysipelas and has recurrent episodes of fever and features of autosomal recessive autoimmunity. In FMF, which is an inflammatory disease, while procoagulant factors increase both during episodes and inter-episode periods, the anticoagulant and fibrinolytic activity decrease. As a result, predisposition to thrombosis occurs.

A 46-year-old female patient, while she was being followed-up because of acute FMF episode in the Rheumatology department, she was admitted to the stroke unit due to the right shift of the mouth, speech disorder, the left side weakness and numbness. In the brain and diffusion Magnetic Resonance (MR) imaging of the patient, it was seen that there was the diffusion restriction in the field irrigated by right middle cerebral artery, and the intra-infarct hematoma on right side at the level of basal ganglia in follow-up.

It was thought to be appropriate to present the case, which applied with ischemic stroke symptom and had development of intra-infarct hematoma in follow-up, due to the coexistence of two clinical forms. There were no similar cases that had coexistence of two different clinical symptoms, in the literature.
\end{abstract}

Keywords: Familial Mediterranean Fever; Stroke; Hematoma; Inflammatory

\section{Introduction}

Familial Mediterranean Fever (FMF) is a hereditary disease that is characterized by fever, peritonitis, arthritis, skin lesions in form of erysipelas and has recurrent episodes of fever and features of autosomal recessive autoimmunity. The gene responsible for FMF is the "Mediterranean Fever (MEFV)", which is located on chromosome 16 p13,3 [1-3]. FMF is especially common among people of Eastern Mediterranean origin, especially Jews, Turks and Arabs. The frequency of affected individuals in these communities ranges from $1 / 250$ to $1 / 1000$ [4]. MEFV encodes a protein called as pyrin. Pyrin is one of the proteins that stimulate both inflammation and apoptosis through Interleukin (IL) $-1 \beta$ and serve in IL-1 inflammatory pathway [2]. It was shown that the negative feedback effect on T helper (Th1) activity and Interferon (IFN) $-\gamma$ may not occur due to defects in pyrin metabolism caused by MEFV gene mutation, and thus, the tendency to proinflammatory state may be formed $[5,6]$.

In FMF, which is an inflammatory disease, while procoagulant factors increase both during episodes and inter-episode periods, the anticoagulant and fibrinolytic activity decrease. As a result, predisposition to thrombosis occurs $[7,8]$.

In the FMF, central nervous system involvement is quite rarely seen. The neurological involvement in FMF is seen at a wide spectrum as pseudotumor cerebri, recurrent aseptic meningitis, ischemic stroke, sinus venous thrombosis, Posterior Reversible Encephalopathy Syndrome (PRES), retinal artery diseases, cranial nerve lesions, optic neuritis, and demyelinating lesions [9-22].

Because there was the coexistence of ischemic stroke and intra-infarct hematoma in this case and there were no similar cases in the literature, this case diagnosed with FMF was planned to be 
Citation: Batum M, Kisabay A, Akgul M, Selcuki D (2018) The Coexistence of Familial Mediterranean Fever and Stroke. Int J Cerebrovasc Dis Stroke : IJCDS-107. DOI: 10.29011/ IJCDS-107. 100007

presented as a Case Study.

\section{Case}

A 46-year-old female patient, while she was being followedup in the Rheumatology department because of acute FMF episode, she was admitted to the stroke unit in neurology clinic after being evaluated by us due to findings of the right shift of the mouth, speech disorder, left side weakness and numbness. The consent form was taken from the relative of the patient.

In the neurological examination of our case, it was seen that the patient was fully conscious and well-oriented and cooperative, the central facial paralysis on the left and the moderate dysarthria was present. It was measured that muscle strength at the upper left extremity was $1 / 5$ and muscle strength at the lower left extremity was $3 / 5$. There was left sided hemihypoesthesia including left half of the face, and it was found that plantar reflex on the left was positive. Physical and systemic examination of the patient were within normal limits. In the background of the patient; hypertension, rheumatoid arthritis and heart failure accompanied FMF.

In control brain Computed Tomography (CT) of the patient; on the left side, a $4 \times 3 \mathrm{~cm}$ diameter hematoma with surrounding edema and a mass were seen at basal ganglia level (Figure-1). In the brain and diffusion Magnetic Resonance (MR) imaging of the patient, it was observed that there was diffusion restriction located in the field irrigated by right middle cerebral artery, and the cerebral hematoma on the right side located at the basal ganglion level and oxy-deoxyhemoglobin stage (Figures 2A, 2B, 2C).

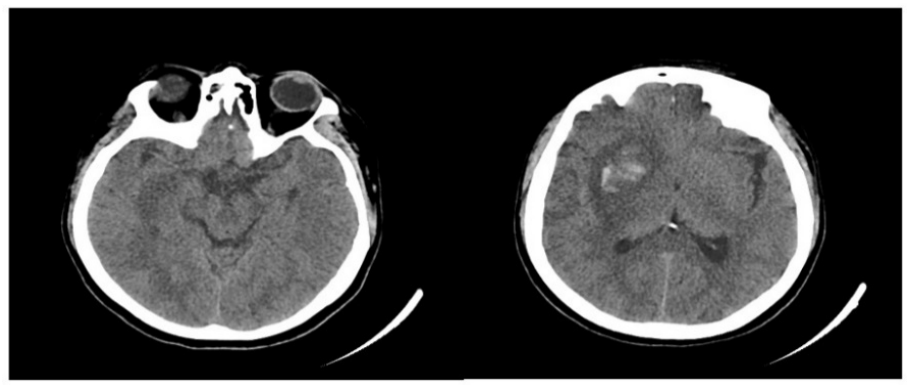

Figure 1: In brain CT examination; on the right side, mass at the basal ganglia level and the $4 \times 3 \mathrm{~cm}$ diameter hematoma with surrounding edema were observed.

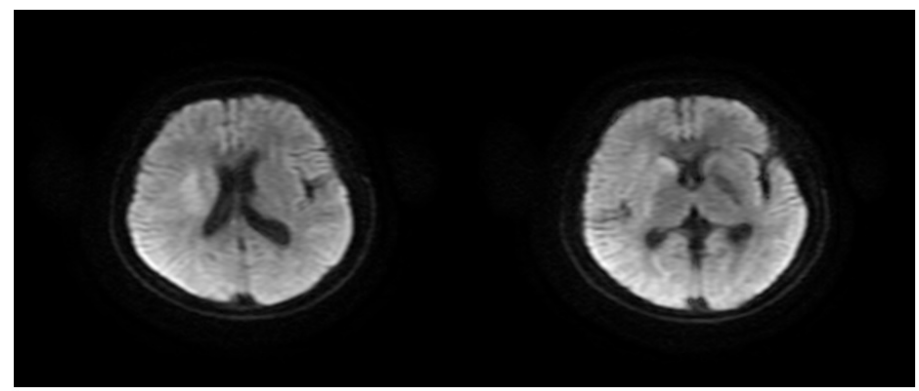

Figure 2A: In Diffusion MRI examination, hyper intense lesion existed on the right side at basal ganglia level.
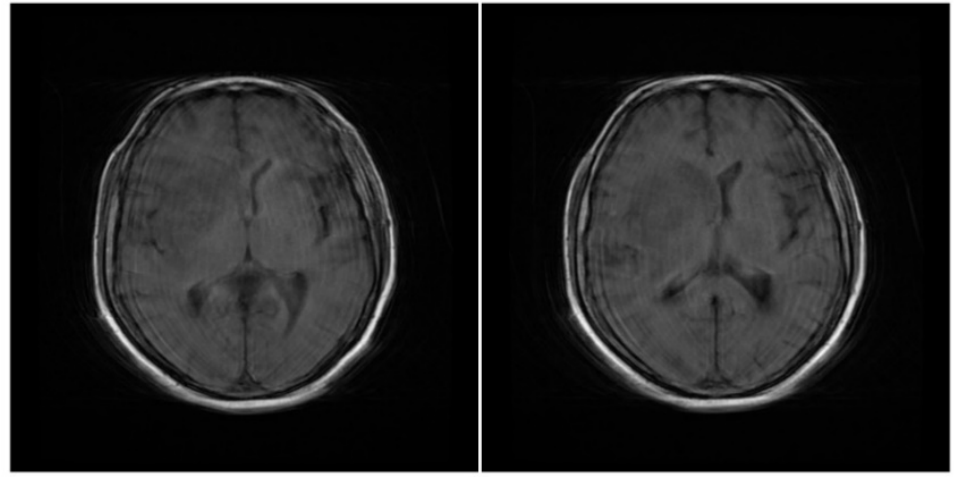

Figure 2B: In T1-weighted sequence images of Cranial MRI; on the right side, the hypo intense lesion existed at the basal ganglia level.
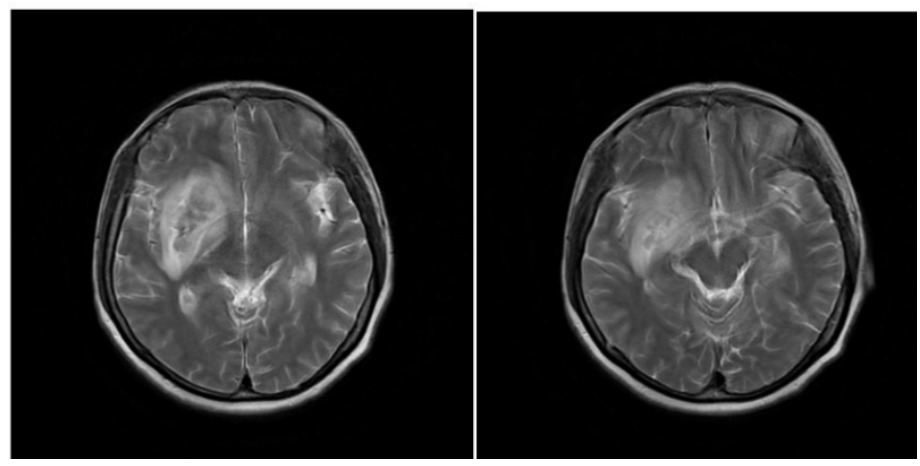

Figure 2C: In T2-weighted sequence images of Cranial MRI; on the right side, there was the heterogeneous image consisted by the hyper intense area at basal ganglion level and the hypo intense area in the interior of these identified regions. 


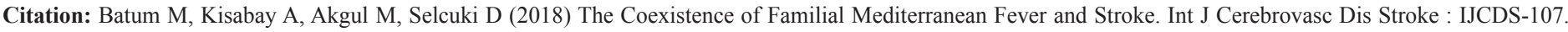
DOI: 10.29011/ IJCDS-107. 100007

In order to investigate the risk factors; hemogram examination, biochemical tests (fasting blood glucose, liver and kidney function tests and electrolytes, lipid profile, thyroid function tests), detailed thrombophilia panel (MTHFR C677T and MTHF A1298C polymorphism Prothrombin G20210A, Factor V Leiden, PAI-1 4G, B-fibrinogen, Factor XIII V34L, GPIIIa L33 P (HPA-1)), coagulation panel (protein $\mathrm{C}$, protein $\mathrm{S}$, antithrombin 3 , resistance to active protein $\mathrm{C}$, fibrinogen and factors), rheumatologic-serological-infectious tests, all vasculitis markers, carotid-vertebral doppler Ultrasonography (USG) were requested. Cardiology consultation and transthoracic Echocardiography (ECHO) were planned.

In the test results; moderate anemia (Hg: 11.2), homocysteinemia (Homocysteine: 21), hypercholesterolemia (LDL: $164 \mathrm{mg} / \mathrm{dL}$ ), Antinuclear Antibody (ANA) positivity, Rheumatoid Factor elevation (RF: 237), moderate fibrinogen elevation (554 $\mathrm{mg} / \mathrm{dL}$ ) and the PAI-14G heterozygous mutation from the thrombophilia panel were detected. No pathology was detected in other coagulation and vasculitis markers. There were normal results in carotid-vertebral doppler USG. In transthoracic echocardiography; the grade 2 mitral regurgitation, the moderate aortic regurgitation, mild hypokinetic left ventricular, concentric left ventricular hypertrophy were detected, and left ventricular ejection fraction was found to be $40 \%$. Other examinations were at normal limits. The treatment for hypertension and heart failure was regulated according to the suggestions of cardiology consultation.

The patient underwent treatment with antiedema and antiaggregant (acetylsalicylic acid $150 \mathrm{mg}$ ) in the stroke unit after diffusional MR. Antiaggregant therapy was discontinued when the intra-infarct hematoma development was seen in examinations of conventional MRI and brain CT scans. There were no risk factors that could lead to hematoma formation. In control brain CT, it was detected that there was a regression in hematoma diameter and edema. After the hematoma was totally reabsorbed, the patient was discharged by taking to the rehabilitation program.

At the polyclinic control performed one month later, it was seen that the patient was fully conscious and well-oriented and cooperative. It was measured that muscle strength at the upper left extremity was 3-4/5 and muscle strength at the lower left extremity was $4-5 / 5$. There was the left sided mild hemihypoesthesia including left half of the face, and it was found that plantar reflex on left was as positive. It was seen that there was a distinct improvement in the central facial paralysis and dysarthria. In the control brain CT, it was seen that the hematoma was totally reabsorbed. Antiaggregant therapy was started at a lower dose (acetylsalicylic acid $100 \mathrm{mg}$ ). Continuation of the rehabilitation program, rheumatology and cardiology checks were recommended for the patient with no additional complaints. The patient did not have any additional complaints at the later follow-up, and bleeding did not recur.

\section{Discussion}

Familial Mediterranean Fever (FMF) is an autoinflammatory, hereditary, multisystem disease with recurrent episodes. The relationship between ischemic cerebrovascular disease and FMF has not been clearly understood and is still under investigation.

After the brain blood flow regulation deterioration, endothelial dysfunction and brain edema development, an increase occurs in endothelial surface proteins and adhesion molecules (P Selectin, E Selectin). Microcirculatory dysfunction develops after the adhesion of leukocytes to this area [23-25]. In the FMF which is an inflammatory disease, it is known that the acute phase reactants and cytokines such as CRP, IL-1, IL-6, and IL-8 increase both during episodes, and inter-episode periods [26]. During FMF episodes; it is observed that there is an increase in levels of Erythrocyte Sedimentation Rate (ESR), fibrinogen, $\alpha 2$ and $\beta$ globulin and serum amyloid A levels. Episodes may be accompanied by neutrophilic leukocytosis $[5,6]$.

As well as the coexistence of FMF and thrombophilia panel disorder, the coexistence ofFMF with vasculitis and/orvasculopathy may be seen. The increase in plasma homocysteine levels caused by MTHFR C677T and MTHFR A1298C polymorphism, PAI homozygous deficiency can lead to vascular disorders and stroke [27,28]. Systemic Lupus Erythematosus (SLE), Acute Rheumatic Fever (ARA), Polyarteritis Nodosa (PAN), Spondyloarthropathies, Behcet's syndrome were among the diseases reported frequently due to the coexistence of FMF with vasculitis and vasculopathies $[16,29,30]$.

After all these changes; in FMF which is an inflammatory disease, procoagulant factors increase both during episodes and inter-episode periods. But the anticoagulant and fibrinolytic activity decrease. As a result, predisposition to thrombosis is frequently seen $[1,31]$. When the carotid arteries were examined, it was seen that there was an increase in the intima media thickness of patients with FMF compared to the control group. This situation showed to us that even if stroke did not occur, there was a predisposition to atherosclerosis [32,33].

In the differential diagnosis of the disease; Hyperimmunoglobulin D Syndrome (HIDS) which is hereditary and characterized by recurrent fever, TNF Receptor-Associated Periodic Syndrome (TRAPS), Familial Cold Autoinflammatory Syndrome (FCAS), PFAPA syndrome (Periodic Fever, Aphthous stomatitis, Pharyngitis, cervical Adenopathy), Behcet's disease, Crohn's disease, Allergic reaction, Hodgkin's disease, Malaria, Lyme are located. When the joint pains are taken into account, Behcet's disease, Reiter's syndrome, ulcerative colitis and Polyarteritis Nodosa (PAN) should be in our minds as diseases which may coexist with FMF [34-36].

Colchicine therapy is used to prevent the episodes and amyloidosis, reduce the inflammation. Colchicine suppresses the 


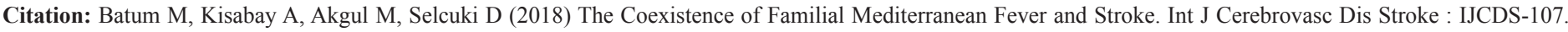
DOI: 10.29011/ IJCDS-107. 100007

formation of inflammation, reduces the severity and frequency of episodes, and also prevents the predisposition to thrombosis [3740].

In a study of case series with central nervous system involvement in the FMF, neurological findings were observed in 18 of 8864 FMF cases, 7 of which were demyelinating diseases, 7 were Cerebrovascular Disease (CVD) and 4 were Posterior Reversible Encephalopathy Syndrome (PRES). All cases with CVD were considered as ischemic stroke. In the etiological examination of these patients; it was detected that 2 patients had patent foramen ovale, 1 patient had thalassemia major, 1 patient had bilateral carotid artery dissection and 2 patients had low HDL $(<30)$ [9].

It was reported that the different sized infarcts on different arterial localizations develop. Infarct areas were frequently seen in the infratentorial region $[9,30,41]$.

Because of the presence of definitive diagnosis and the genetic analysis in our patient; in addition to the FMF coexistence of diseases mentioned in the literature, all other young-age stroke causes were investigated. Because especially the presence of positivity in the thrombophilia panel, inflammatory and vasculitis markers increases the predisposition to thrombosis, a detailed examination was performed for the atherosclerosis. In the examinations of the patient with the background involving the hypertension and heart failure, no significant pathology was found except moderate inflammation.

It was reported that central nervous system involvement in FMF may be due to vasculitis and amyloidosis. Amyloidosis can cause both bleeding and ischemia, but it causes much more the bleeding. It was also thought that in our case the amyloidosis may accompany and the bleeding may occur due to the use of antiaggregant therapy.

Since there is no Susceptibility Weighted Imaging (SWI) sequence on the Cranial MRI examination of our case and it is not routinely performed, we do not have clear idea of whether or not there are microbleeds. In such cases, if possible, the presence of SWI sequence performed in MRI would also help in the regulation of the treatment. This case showed us that in FMF-diagnosed patients the amyloidosis should not be forgotten; and the physicians should be careful in antiaggregant and/or anticoagulant therapy.

The other reason that increases the predisposition to bleeding is the presence of hypertension. Although hypertension is present in the patient's background, the elevations in arterial blood pressure were not detected during the period of the clinic development or follow-up.

An interesting aspect of our case was the coexistence of both ischemic and hemorrhagic vascular events in the central nervous system. When the literature was reviewed, it was seen that there was no a case of FMF in which the both situations were seen at same time. Since we should be more careful in regulating the treatment of such cases, this case was found appropriate to be presented.

\section{References}

1. Sav T, Özbakır Ö, Keleştimur F, Gürsoy S, Baskol M, et al. (2006) Adrenal axis functions in patients with familial mediterranean fever. Clin Rheumatol 25: 458-461.

2. Lachmann HJ, Segul B, Yavuzsen TU, Booth DR, Booth SE, et al. (2006) Clinical and subclinical inflammation in patients with Familial Mediterranean Fever and in heterozygous carriers of MEFV mutations. Rheumatology (Oxford) 45: 746-750.

3. Touitou I (2001) The spectrum of Familial Mediterranean Fever (FMF) mutations. Eur J Hum Genet 9: 473-483.

4. Cobankara V, Kiraz S (2000) Ailesel Akdeniz Ateşi. Hacettepe Tıp Dergisi 31: 310-319.

5. Ben-Zvi I, Livneh A (2011) Chronic inflammation in FMF: markers, risk factors, outcomes and therapy. Nat Rev Rheumatol 7: 105-112.

6. Korkmaz C, Ozdogan H, Kasapcopur O, Yazici H (2002) Acute phase response in familial Mediterranean fever. Ann Rheum Dis 61: 79-81.

7. Akdogan A, Calguneri M, Yavuz B, Arslan EB, Kalyoncu U, et al. (2006) Are familial Mediterranean fever (FMF) patients at increased risk for atherosclerosis? Impaired endothelial function and increased intima media thickness are found in FMF. J Am Coll Cardiol 48: 2351-2353.

8. Esmon CT (2003) Inflammation and thrombosis. J Thromb Haemost 1: $1343-1348$.

9. Kalyoncu U, Eker A, Oguz K, Kurne A, Kalan I, et al. (2010) Familial Mediterranean Fever and Central Nervous System Involvement-A case Series. Medicine 89: 75-84.

10. Aksu K, Keser G (2011) Coexistense of vasculitides with Familial Mediterranean Fever. Rheumatol Int 31: 1263-1274.

11. Najim al-Din AS, Mubaidin A, Wriekat AL, Alqam M (1994) Risk factors of aseptic intracranial venous occlusive disease. Acta Neurologica Scandinavica 90: 412-416.

12. Gokalp HZ, Baskaya MK, Aydin V (1992) Pseudotumor cerebri with familial Mediterranean fever. Clin Neurol Neurosurg 94: 261-263.

13. Lossos A, Eliashiv S, Ben-Chetrit E, Reches A (1993) Optic neuritis associated with familial Mediterranean fever. J Clin Neuroophthalmol 13: $141-143$.

14. Ozkaya O, Bek K, Alaca N, Ceyhan M, Acikgoz Y, et al. (2007) Cerebral vasculitis in a child with Henoch-Schonlein purpura and familial Mediterranean fever. Clin Rheumatol 26: 1729-1732.

15. Baysun S, Demircin G, Erdodan O, Bulbul M, Yildiz YT, et al. (2008) Multiple visceral hematomas in a child with familial Mediterranean fever: polyarteritis nodosa. Pediatr Nephrol 23: 1235-1237.

16. Schwartz T, Langevitz P, Zemer D, Gazit E, Pras M, et al. (2000) Behcet's disease in Familial Mediterranean fever: characterization of the association between the two diseases. Semin Arthritis Rheum 29: 286 295. 
Citation: Batum M, Kisabay A, Akgul M, Selcuki D (2018) The Coexistence of Familial Mediterranean Fever and Stroke. Int J Cerebrovasc Dis Stroke : IJCDS-107. DOI: 10.29011/ IJCDS-107. 100007

17. Finsterer J, Stollberger C, Shinar Y (2002) Cranial nerve lesions and abnormal visually evoked potentials associated with the M694V mutation in familial Mediterranean fever. Clin Rheumatol 21: 317-321.

18. Ugurlu S, Bolayir E, Candan F, Gumus C (2009) Familial Mediterranean fever and multiple sclerosis-a case report. Acta Reumatol Port 34: 117-119.

19. Guinet A, Grateau G, Nifle C, Rozier A, Pico F (2008) Multiple sclerosis and familial Mediterranean fever: a case report. Rev Neurol 164: 943-947.

20. Topcuoglu MA, Karabudak R (1997) Familial Mediterranean fever and multiple sclerosis. J Neurol 244: 510-514.

21. Aoun EG, Musallam KM, Uthman I, Beydoun A, El-Hajj T, et al. (2009) Childhood stroke in a child with familial Mediterranean fever carrying several prothrombotic risk factors. Lupus 18: 845-847.

22. Collard M, Sellal F, Hirsch E, Mutschler V, Marescoux C (1991) Recurrent aseptic meningitis in periodic disease or Mollaret's meningitis? Rev Neurol 147: 403-405.

23. Cetin G, Utku U, Atilla N, Gişi K, Sayarlıoglu M (2016) Changes in the Cerebral Blood Flow Velocity in Patients with Familial Mediterranean Fever. Arch Neuropsychiatr 1: 1-3.

24. Pober JS, Sessa WC (2007) Evolving functions of endothelial cells in inflammation. Nat Rev Immunol 7: 803-815.

25. Badolato R, Wang JM, Murphy WJ, Lloyd AR, Michiel DF, et al. (1994) Serum amyloid $A$ is a chemoattractant: induction of migration, adhesion, and tissue infiltration of monocytes and polymorphonuclear leukocytes. J Exp Med 180: 203-209.

26. Gang N, Drenth JP, Langevitz P, Zemer D, Brezniak N, et al. (1999) Activation of the cytokine network in familial Mediterranean fever. $J$ Rheumatol 26: 890-897.

27. Dikmen M (2004) [Homocysteine metabolism and association with diseases: A review]. Turkiye Klinikleri J Med Sci 24: 645-652.

28. Karatay S, Yildirim K, Uyanik A, Uzkeser H, Kiziltunc A, et al. (2010) Increased Serum Concentrations of Homocysteine and Lipoprotein (a) in Familial Mediterranean Fever. Ann Clin Lab Sci 40: 10-14.

29. Aksu K, Keser G (2011) Coexistense of vasculitides with Familial Mediterranean Fever. Rheumatol Int 31: 1263-1274.
30. Luger S, Harter PN, Mittelbronn M, Wagner M, Foerch C (2013) Brain stem infarction associated with familial Mediterranean fever and central nervous system vasculitis. Clin Exp Rheumatol 31: 93-95.

31. Onen F (2006) Familial Mediterranean fever. Rheumatol Int 26: 489496.

32. Peru H, Altun B, Doğan M, Kara F, Elmaci AM, et al. (2008) The evaluation of carotid intima-media thickness in children with Familial Mediterranean Fever. Clin Rheumatol 27: 689-694.

33. Bilginer Y, Ozaltin F, Basaran C, Duzova A, Besbas N, et al. (2008) Evaluation of intima media thickness of the common and internal carotid arteries with inflammatory markers in familial Mediterranean fever as possible predictors for atherosclerosis. Rheumatol Int 28: 12111216.

34. Erdem H, Şimşek İ, Pay S, Dinç A, Deniz Ö, et al. (2006) Diffuse Pulmonary Amyloidosis That Mimics Interstitial Lung Disease in a Patient With 66 Familial Mediterranean Fever. J Clin Rheumatol 12: 34 $\square 36$.

35. Federici L, Rittore-Domingo $C$, Koné-Paut I, Jorgensen $C$, Rodière $M$, et al. (2006) A decision tree for genetic diagnosis of hereditary periodic fever in unselected patients. Ann Rheum Dis 65: 1427-1432.

36. Kınıkı G (2006) [Differantial diagnosis of Familial Mediterranean Disease]. Turkiye Klinikleri J Int Med Sci 2: 40-45.

37. Özdoğan H (2006) Ailevi Akdeniz Ateşi Tedavisi ve Prognozu.Türkiye Klinikleri J Int Med Sci 2: 51凸56.

38. Zemer D, Livneh A, Danon YI, Pras M, Sohar E (1991) Long term colchicine treatment in children with FMF. Arthr Rheum 34: 973-977.

39. Ben-Chetrit E (2003) Familial Mediterranean fever (FMF) and renal AA amyloidosis-phenotype-genotype correlation, treatment and prognosis. J Nephrol 16: 431-434.

40. Duzova A, Bakkaloglu A, Besbas N, Topaloglu R, Ozen S, et al. (2003) Role of A-SAA in monitoring subclinical inflammation and in colchicine dosage in familial Mediterranean fever. Clin Exp Rheumatol 21: 509514 .

41. Akpınar Z, Guney F, Tokgöz S (2014) Familial Mediterranean Fever and Cerebral Ischemia: Case Report. Turkiye Klinikleri J Case Rep 22: 46-49. 